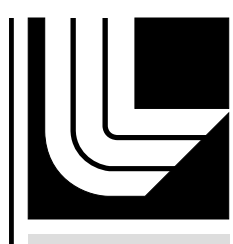

LAWRENCE LIVERMORE N A TIO NAL LABORATORY

High-Energy Beams for Simulating High-Yield Nuclear Events

R. Kirkwood

November 16, 2012 
This document was prepared as an account of work sponsored by an agency of the United States government. Neither the United States government nor Lawrence Livermore National Security, LLC, nor any of their employees makes any warranty, expressed or implied, or assumes any legal liability or responsibility for the accuracy, completeness, or usefulness of any information, apparatus, product, or process disclosed, or represents that its use would not infringe privately owned rights. Reference herein to any specific commercial product, process, or service by trade name, trademark, manufacturer, or otherwise does not necessarily constitute or imply its endorsement, recommendation, or favoring by the United States government or Lawrence Livermore National Security, LLC. The views and opinions of authors expressed herein do not necessarily state or reflect those of the United States government or Lawrence Livermore National Security, LLC, and shall not be used for advertising or product endorsement purposes.

This work performed under the auspices of the U.S. Department of Energy by Lawrence Livermore National Laboratory under Contract DE-AC52-07NA27344. 


\section{High-Energy Beams for Simulating High-Yield Nuclear Events Robert Kirkwood}

In FY12 we optimized the plan for a target that can combine six quads of beams into a single beam and did initial target design calculations. A gas filled tube with windows was illuminated with the 6 beams and an additional 10 heater beams in a HYDRA simulation. The efficiency of beam transmission through the entire plasma profile and the gain for the energy transfer process were analyzed. The target design produced shows that absorption can be kept to $30 \%$ with only 10 percent in the plasma column where the beam amplification occurs and $20 \%$ in the wings of the profile. The peak SBS gain is also sufficient for power transfer under the simulated conditions. Further work will optimize the heater pointing to produce the uniform profile and further minimize absorption in the wings.

The work performed this year has shown the feasibility of producing high transmission plasmas that can combine five or more quads at NIF, and has already produced a target design adequate for testing at NIF. The mid year start of this program necessitated some of the further work on optimizing the target be done in the following year. When complete, the target designed by this program will be tested on NIF as part of the present EPEC program with the results used to propose additional high energy EPEC experiments to NA22 and other interested agencies.

This work was performed under the auspices of the U.S. Department of Energy by Lawrence Livermore National Laboratory under Contract DE-AC52-07NA27344. LLNL-TR-602552 